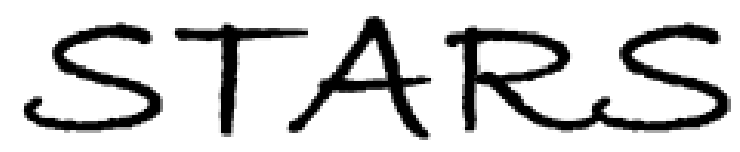

University of Central Florida

STARS

Faculty Bibliography 2010s

Faculty Bibliography

$1-1-2015$

\title{
Counseling Multiple-Heritage Couples
}

Ashley J. Blount

University of Central Florida

Mark E. Young

University of Central Florida

Find similar works at: https://stars.library.ucf.edu/facultybib2010

University of Central Florida Libraries http://library.ucf.edu

This Article is brought to you for free and open access by the Faculty Bibliography at STARS. It has been accepted for inclusion in Faculty Bibliography 2010 s by an authorized administrator of STARS. For more information, please contactSTARS@ucf.edu.

\section{Recommended Citation}

Blount, Ashley J. and Young, Mark E., "Counseling Multiple-Heritage Couples" (2015). Faculty Bibliography 2010s. 6428.

https://stars.library.ucf.edu/facultybib2010/6428

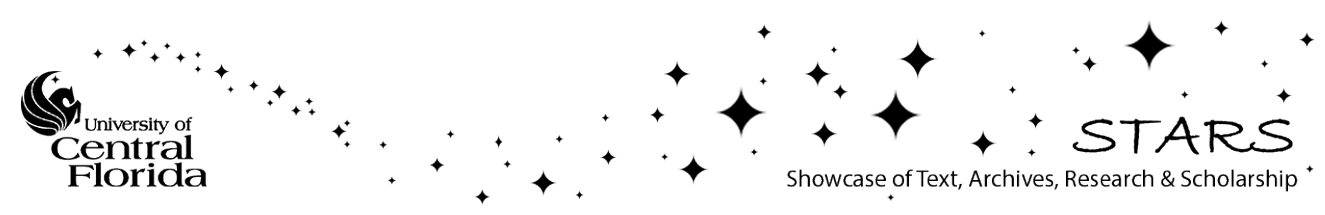




\title{
application: theory to culturally competent practice
}

\section{Counseling Multiple-Heritage Couples}

\begin{abstract}
Ashley J. Blount and Mark E. Young
Multiple-heritage couples are one of the fastest growing client populations in the United States. These partnerships are defined by intersecting ethnic, racial, linguistic, and religious differences. They are challenged by societal perceptions, stereotypes, and other pressures associated with being in a multiple-heritage pairing. This article discusses strengths in the multipleheritage union brought about by the understanding of diverse viewpoints. Finally, the article identifies specific strategies, such as couples relationship education, to resolve and confront inherent differences.

Keywords: multiple heritage, multicultural, couples, counseling

Las parejas multiculturales son uno de los grupos demográficos de clientes de mayor crecimiento en los Estados Unidos. Este tipo de parejas se define por la intersección de diferencias étnicas, raciales, lingüísticas y religiosas. Sus miembros enfrentan desafíos a causa de las percepciones sociales, los esterotipos y otras presiones asociadas con tener una pareja multicultural. Este artículo discute los puntos fuertes en una unión multicultural, facilitados por la comprensión de puntos de vista diversos. Finalmente, el artículo identifica estrategias específicas, como por ejemplo la educación en relaciones de pareja, para resolver y afrontar las diferencias intrínsecas.
\end{abstract}

Palabras clave: multicultural, parejas, consejería

$\mathrm{R}$ esearch and clinical interest in couples counseling has burgeoned in the past 20 years (Messer \& Gurman, 2011), making it one of the psychotherapists seeing and treating clients as couples (Lebow, Chambers, Christensen, \& Johnson, 2012). Couples counseling is a difficult form of counseling and requires additional skills, knowledge, and techniques distinct from individual counseling (Long \& Young, 2007). Some of the challenges that make couples therapy unique are (a) couples do not have an individual bond with the counselor, (b) couples tend to argue during the session and often have recurring maladaptive patterns of interaction, (c) couples may have a long history of conflict and hidden agendas within their relationship unknown to the counselor, and (d) couples often wait to seek counseling until their problems are profoundly influencing their partnership (Gottman,

Ashley J. Blount and Mark E. Young, Department of Child, Family, and Community Sciences, University of Central Florida. Correspondence concerning this article should be addressed to Ashley J. Blount, Department of Child, Family, and Community Sciences, University of Central Florida, PO Box 161250, Orlando, FL 32816-1250 (e-mail: ashleyjwindt@knights.ucf.edu).

(C) 2015 American Counseling Association. All rights reserved. 
1999; Long \& Young, 2007). As William Doherty (2002) said, “A dirty little secret in the therapy field is that couples therapy may be the hardest form of therapy, and most therapists aren't good at it" (p. 9). Thus, even experienced counselors familiar with individual counseling may be unprepared for the unique challenges of the couples session.

Beyond the difficulties inherent in couples counseling, couples from different backgrounds may also encounter complex relationship problems due to conflicting racial identities, ethnicities, religious perspectives, languages, or places of origin (Henricksen \& Paladino, 2009; Olver, 2012). Although cultural differences between partners have been a topic of research and clinical interest for many years (cf. Mansikka \& Fukuyama, 1985), demographics are changing. As the United States becomes increasingly diverse, the number of interethnic relationships is on the rise (Wright, Houston, Ellis, Holloway, \& Hudson, 2003). The prevalence of interracial couples, for example, increased from $0.4 \%$ in 1960 to 2.2\% in 1990 (Wright et al., 2003). By the year 2000, interracial pairings had reached $5.4 \%$ (U.S. Census Bureau, 2003). More recently, $14.6 \%$ of new marriages within the United States were mixed across ethnicity, with about $25 \%$ of Hispanics, $10 \%$ of Whites, and $15 \%$ of Blacks marrying someone of a different ethnicity (Chartier \& Caetano, 2012).

Another illustration of the changing landscape is that we are seeing an increase in the number of individuals who say they are or would be willing to marry outside of their religious orientation (Pew Research Center, 2009). One in four Americans are now married or cohabiting with a partner of a different religious background (Pew Research Center, 2009). Religious differences can be significant because both partners may feel strongly about attendance at services, dietary restrictions, and rites and rituals of their particular faith (Weld \& Eriksen, 2006). In short, the likelihood of couples having differences across additional heritage domains (e.g., religion, gender, place of origin) is also increasing, and it is important for practicing counselors to be aware that couples combining different heritages are likely to be significantly more common in the counseling setting (Chung, Bemak, Ortiz, \& Sandoval-Perez, 2008).

In this article, the term multiple-heritage individual is used to describe a person who possesses "multiple aspects of heritage, including race, ethnicity, religion, language, gender, and national origin” (Henricksen \& Paladino, 2009, p. xiii). Thus, multiple-heritage couples refer to couples in which there is a difference in background on these dimensions. Multiple heritage can encompass couples that are different merely in religion or ethnicity but are not racially different. The term also includes couples in which both members are not only different racially but also different in other important background issues. The need for a new term in couples work is to alert the counselor to look deeper and be aware of multiple influences rather than focusing purely on racial appearance. It could spur more interest in considering the entire spectrum of multicultural differences that influence a couple and provide a focus for research. Nevertheless, whereas multiple heritage is seen as more inclusive than biracial, multiracial, and interethnic, these older terms are the more 
dominant in the literature and are the source of support for many of the arguments and examples in this article. Besides promoting new terminology, this article reviews the potential challenges encountered by multiple-heritage couples due to ethnic, racial, linguistic, and religious differences. It also discusses societal perceptions, stereotypes, and pressures associated with being in a multiple-heritage pairing. Finally, potential strengths of multiple-heritage unions are presented and implications for counselors are discussed.

\section{societal response}

Historically, unions between diverse individuals have been met with distrust, skepticism, and increased scrutiny (Kenney \& Kenney, 2012). As recently as 50 years ago, the United States had laws in place preventing interracial marriage, and it was not until the 1967 landmark Loving v. Virginia case that the Supreme Court banned all laws preventing such pairings (Kenney \& Kenney, 2012). Although interracial relationships are now legal, couples entering relationships across racial, ethnic, religious, and language lines may still violate societal norms (Killian, 2003; Lewis, Yancey, \& Bletzer, 1997; Root, 2001). In 2003, 33\% of Americans disapproved of interracial marriages, and, as a result, multiple-heritage couples experienced marginalization of their relationships from family, friends, and society (Killian, 2003). According to the Pew Research Center (2012), however, tolerance of multiple-heritage partnerships is increasing in the United States.

Today, more couples fall under the heading of multiple heritage, and there is generally more acceptance. Still, as members become intimately involved, committed to each other, or married, they often face family disapproval and societal opposition (Henricksen \& Paladino, 2009; Killian, 2003; Root, 2001). In general, people are comfortable supporting multiple-heritage pairings in public but remain apprehensive when it influences them personally (i.e., when it involves a family member or close friend, involves sexual intimacy, or includes marriage; Qian \& Licther, 2007). Furthermore, multiple-heritage partnerships are typically viewed by the public as dysfunctional in comparison with homogeneous partnerships (Bratter \& King, 2008). As a result, those within multiple-heritage relationships may face disapproval and negative evaluation by family, friends, and society as the seriousness of the relationship increases.

\section{myths and misconceptions}

Multiple-heritage pairings are surrounded by societal myths and misconceptions (Henricksen \& Paladino, 2009). To illustrate, Kenney and Kenney (2012) identified several of the myths about why a person enters into an interracial partnership. Among these myths are to make a statement, curiosity, promiscuity, raising one's status, domination, citizenship, low self-esteem, and rebellion. The myths tend to portray individuals who enter into multiple-heritage relationships as doing so because of immaturity or personal gain. Similarly, 
reasons for entering into multiple-heritage pairings are challenged and questioned by families and friends more frequently than reasons for entering into same-heritage relationships (Killian, 2001a). These preconceptions convey to the couple that they are destined to a life of confusion and rejection (Kenney \& Kenney, 2012). At the same time, significant others do not take time to gain an understanding of the multiple-heritage relationship (Killian, 2002). Thus, many multiple-heritage couples begin their lives without the blessing of family support systems and face skepticism that may affect the quality and stability of their relationship.

\section{relationship quality}

Multiple-heritage marriages have increased in the United States since the 1970s (Qian \& Licther, 2007), and estimates of the quality of their relationships have varied in the literature (Hohmann-Marriott \& Amato, 2008). On the one hand, research supports the idea that multiple-heritage relationships are similar to or of higher quality than same-heritage pairings (e.g., Forry, Leslie, \& Letiecq, 2007; Fu, 2001; Hohmann-Marriott \& Amato, 2008). However, Hohmann-Marriott and Amato (2008) suggested five factors that might influence relationship quality in multiple-heritage pairings: (a) complex relationship histories, (b) differing socioeconomic resources available, (c) additional differences (i.e., having more than one heritage difference within a couple), (d) diverse attitudes and values, and (e) decreased social and external support. On the basis of these findings, it appears that an assessment of a couple's background is critically important to understanding how to improve the couple's relationship quality. Specifically, the counselor must be able to understand the couple within their particular religious, familial, cultural, and lingual contexts (Qian, Blair, \& Ruf, 2001) and view threats and supports to relationship quality as unique to each relationship.

\section{marital dissolution, stability, and divorce}

Relationship stability is thought to be lower for multiple-heritage couples than for same-heritage pairings, meaning that these relationships are thought to be more divorce prone (Negy \& Snyder, 2000). It is often assumed that couples sharing similar heritages, backgrounds, characteristics, and belief systems have fewer conflicts and misunderstandings (Bratter \& King, 2008; Zhang \& Van Hook, 2009). As a result, multiple-heritage couples with more diverse backgrounds have more avenues for conflict and could have less stable relationships and marriages (Zhang \& Van Hook, 2009).

Zhang and Van Hook (2009) found that, on average, multiple-heritage marriages are indeed less stable than same-heritage marriages. Multiple-heritage couples are likely to have more struggles, challenges, and misunderstandings 
due to the external disapproval of their relationship and the internal dissimilarities within their relationship (Negy \& Snyder, 2000). Consequently, multiple-heritage couples are assumed to have less relational and marital stability than same-heritage couples.

Building on these assumptions from previous research, Bratter and King (2008) investigated marital stability and the likelihood of divorce in interracial couples and found that interracial marriages had higher rates of divorce than intraracial marriages. Similarly, additional cultural differences in multiple-heritage marriage might lead to increased levels of stress, greater instability, and decreased marital quality (Negy \& Snyder, 2000). Furthermore, spousal dissimilarity relating to beliefs, values, behaviors, and perspectives in couples has been found to contribute to incompatibility within multiple-heritage relationships and could contribute to marital dissolution (Clarkwest, 2007).

In summary, marriage or partnership across heritages can carry individual, couple, and systemic consequences that affect relationship quality, levels of dissolution, relationship stability, and the likelihood of divorce (Killian, 2003). Opposition, a lack of support, external resistance to multiple-heritage partnerships, and societal stereotyping are examples of potential threats multiple-heritage couples might face. Furthermore, multiple-heritage couples that decide to marry may be met with increased levels of discrimination, as well as ostracism from friends, family, and society (Killian, 2001b, 2002).

\section{relationship concerns}

\section{COUPLE DISTRESS}

Root (2001) noted that multiple-heritage couples face higher levels of conflict and distress in their relationships than same-heritage couples as a result of gender, personal, social, and socioeconomic differences. One way this may manifest is in attitudes toward infidelity. Infidelity is a common issue yet one that causes significant distress and instability in a relationship (Long \& Young, 2007; Penn, Hernandez, \& Bermudez, 1997). For the multiple-heritage couple, infidelity is a prototypical problem because the meaning of infidelity is culturally loaded. For example, norms and values regarding infidelity, religious perspectives, societal views, and racial and ethnic perspectives on infidelity are heavily influenced by cultural perceptions (Penn et al., 1997).

For example, one member of the couple may view sexual infidelity as acceptable as long as the partner is not publicly humiliated, whereas the other partner views it as the end of the marriage as a result of his or her different upbringing. Such perspectives are inherited from one's family and culture. To illustrate, consider treating an American man and his Brazilian wife, who are on the verge of divorce because he flirted with a woman at a party. For the wife, flirting could be tantamount to infidelity. Couples may fail to discuss the definition of infidelity and their familial and cultural positions until a 
crisis arrives. Multiple-heritage couples may need to have more discussions than couples that draw from the same cultural well.

Another factor influencing multiple-heritage couples is socioeconomic status disparities. Education and income differences are associated with couple distress and disruption of the multiple-heritage union (Bratter \& King, 2008; Lewis et al., 1997). Furthermore, individuals entering a multiple-heritage relationship with differing levels of education and socioeconomic resources may find an imbalance in the relationship and face increased levels of relationship distress (Lewis et al., 1997).

\section{CULTURAL SALIENCE AND ACCULTURATION}

An emerging issue in multicultural counseling is the issue of cultural salience (Kwan, 2005). Salience in this context means the importance one places on one's cultural heritage (Suzuki \& Ponterotto, 2008). Whereas acculturation describes a person's degree of orientation to the majority culture versus one's ethnic culture (Yoon, Langrehr, \& Ong, 2011), salience refers to the attraction and allegiance to a cultural identity. Thus, even couples with similar degrees of acculturation (e.g., first-generation Italian Americans) might have a different degree of love or acceptance for their Italian heritage.

Both acculturation differences and differences in salience can be troublesome for couples. Consider an Asian Indian couple in which one parent wants their children to become Americanized so that they can be accepted. They give them American names and have them adopt American dress and diet. The other parent is a traditional Hindu vegetarian who wants the children to retain their cultural identities. For one parent, being Indian is an important part of what should be transmitted to their children. For the other, fitting in is crucial. One potential result is a divided household with mixed messages and potential conflict between the parents. If the difference is of concern for the couple, an assessment of acculturation and cultural salience can be important in understanding and treating concerns as they arise (Frame, 2004).

\section{CONFLICT AND VIOLENCE}

Multiple-heritage couples may be at a higher risk for conflict and intimate partner violence than same-heritage couples (Chartier \& Caetano, 2012). Zhang and Van Hook (2009) asserted that couples similar in ethnicity, education, age, or religion experience less conflict; thus, higher conflict couples might be more prone to violence. Furthermore, individuals in interethnic pairings tend to be younger (Chartier \& Caetano, 2012). Impulsivity in younger age groups has been related to intimate partner violence (Carbone-Lopez, Rennison, \& Macmillan, 2012) and thus might account for an association between multiple-heritage couples and increased levels of conflict and partner violence.

Relationship violence can manifest in a number of ways, including verbal fighting and physical altercations (Carbone-Lopez et al., 2012). In some cultures, partner violence is more acceptable and is, in fact, an expected response 
to dishonor (Carbone-Lopez et al., 2012). In a culture in which honor is a central value, infidelity, for example (especially female infidelity), can serve as motivation for violence to punish or to reestablish honor and status within a family (Vandello \& Cohen, 2003). Vandello and Cohen (2003) described honor as a cultural syndrome that includes a combination of good moral character, integrity, social status, and reputation.

Furthermore, how individuals react to partner violence and relationship outcomes associated with violence varies across cultures and within relationships (Yamawaki, Ochoa-Shipp, Pulsipher, Harlos, \& Swindler, 2012). In some cultures, partner violence is socially acceptable and the victim of violence is praised for loyalty when he or she remains in the relationship (Yamawaki et al., 2012). In other cultures, individuals who are exposed to violence are expected to leave the relationship and are viewed negatively if they choose otherwise (Vandello \& Cohen, 2003). For multiple-heritage couples, differing cultural perceptions may influence how these individuals deal with and work through occurrences of violence within the relationship.

\section{CHALLENGES OF MULTIPLE-HERITAGE CHILD REARING}

Differences within multiple-heritage dimensions (i.e., background, ethnicity, race, language, and religion) can make raising a child a difficult process (Byrd \& Garwick, 2006). Collaboration in parental decision making can be challenging because of contrasting approaches to parenting, how to ethnically or racially identify children, and how to raise children with regard to religion (Kukutai, 2007). An example includes one parent who believes that children should go to confession following misbehavior, whereas the other parent does not believe in religious confession as a disciplinary action. Conflicting parenting styles and cultural expectations in the home may create confusion in children and produce partner conflict.

Racial and ethnic identification as part of child rearing is a unique challenge for multiple-heritage couples (Kukutai, 2007). Their children are exposed to environmental factors such as schooling, media, and peers that influence identification with one culture or another. Other influences include bilingualism, generational status (i.e., how many generations the individual has lived in a particular area), and proximity to a non-White community (Lee \& Bean, 2004). One of the most difficult challenges multiple-heritage parents face is helping their child to develop a coherent cultural identity. Multiple-heritage parents and children often solve this issue by selecting one side of their heritage with which to identify (Lee \& Bean, 2004). In a Christian/Jewish couple for example, when a child reaches the teenage years, the bar mitzvah or bat mitzvah signals a decision point as to how the child will identify religiously. At that juncture, parents may feel forced to choose to raise the child in the Christian or Jewish faith. Parents may also promote a certain ethnic identity for the child based on physical characteristics, because of pressure from extended family, or because they feel the child will be more accepted in society (Lee \& 
Bean, 2007). On the other hand, the child may feel differently, promoting a conflict between parent(s) and child.

Another challenge for multiple-heritage parents is the external stereotyping of their children (Kukutai, 2007). There are societal and family pressures to choose specific labels and place oneself into distinct categories with regard to race, religion, and primary language spoken. Thus, fitting into one category or another may be difficult for multiple-heritage parents and their children because they may have features that are not as racially distinctive as sameheritage families (Byrd \& Garwick, 2006). Even extended family members may not embrace children of multiple-heritage parents (Byrd \& Garwick, 2006), especially if the child does not resemble other members of the family (Kenney \& Kenney, 2012). In addition, children may speak multiple languages or believe in two religions or a hybrid form of religion. As a result, children of multiple-heritage parents may feel forced to make choices regarding racial and ethnic labeling and may face increased disapproval of their choices by those around them (Lorenzo-Blanco, Bares, \& Delva, 2013).

\section{strengths of multiple-heritage relationships}

Although there are certainly challenges in the multiple-heritage relationship, there are also advantages (Henricksen \& Paladino, 2009). Diverse heritages can promote well-rounded parenting styles in which both parents contribute complementary perspectives to their relationship (Henricksen \& Paladino, 2009). For example, parents bring different ideas, opinions, and behaviors to the couple relationship that can subsequently result in greater creative problem solving as issues arise. For example, during a session at our clinic, one member of a couple remarked, "What I like about her is that she always brings me something different. She has educated me about her Cuban food and history . . . the whole culture." Children may also gain by becoming fluent in more than one culture. For example, they may speak more than one language and be able to easily move into both cultural settings. Additionally, multiple-heritage influences could lead to a more open perspective, increased cultural sensitivity, empathy, and tolerance for both the couple and their offspring (Henricksen \& Paladino, 2009).

Although the pressures affecting their relationship may be greater, multiple-heritage couples may also have a stronger bond as a result of joining together against negative societal reactions (Byrd \& Garwick, 2006). Similarly, societal pressures, stress related to negative stigmas, and the myths and misconceptions surrounding multiple-heritage couples could lead to increased emotional connectedness (Negy \& Snyder, 2000). Moreover, some writers contend that dealing with such rejection helps a couple to be more resilient and could increase the couple's ability to cope with adversity (Negy \& Snyder, 2000). 
Another strength found in multiple-heritage couples is their ability to adjust to others and deal with ambiguous situations. The unique backgrounds, languages, religious perspectives, and ethnicities that multiple-heritage individuals bring to their partnerships make adjustment a crucial component of the relationship. For example, one couple who came to our clinic for counseling was conflicted about the role of family in their couple relationship. One member was an Asian Indian and her partner was an American Jewish man. For her, a night out involved all her sisters and mother-never just the couple. On the other hand, an ideal night out for him involved just the two of them spending time together. With time, however, the couple was able to carve out space for themselves, and, interestingly, the man was aware of how rich and diverse his life had become and how less isolated he felt in this extended family. Although there is not yet much research support for some of these conclusions, from a clinical perspective, helping the couple to identify relationship strengths can be an important form of encouragement (Long \& Young, 2007).

\section{implications for counselors \\ ASSESSMENT AND TREATMENT PLANNING}

Thus far, a number of issues have been outlined that affect the lives of multipleheritage couples. Many of the suggestions as to directions for the counselor have to do with assessment. It is proposed that the counselor must have a somewhat comprehensive understanding of each person's ethnic, racial, and spiritual/religious background before and during the counseling process (Arrendondo \& Perez, 2006; Skiba, Knesting, \& Bush, 2002). A structured assessment of each person's background can provide a thorough understanding of how much agreement or acceptance each member has for the other's position. Counselors may presume that because a couple is together they have embraced the other's background, yet they may not have really accepted each other's language, culture, religion, or history (Romano, 2008). This conflict may become a conflict to address in the couple's therapy.

One approach is to assess each person's heritage and beliefs in front of the other, followed by a discussion with the couple about how they will resolve conflicts and capitalize on strengths. According to Kluckhohn and Strodtbeck (1961), people's attitudes are based on their relatively stable value systems. In a popular book by Crohn (1995), the couple is encouraged to share with each other the cultural norms and attitudes around six issues: time (Which is more important: past, present, or planning for the future?), human nature (Are people good, evil, trustworthy?), cohesiveness of the family (Should our family have a separate life, be enmeshed with the families of origin, or somewhere in between?), emotional expressiveness (To what extent should emotions be expressed?), individuals versus the family (Whose needs take precedence: the individual's or the family's?), and gender roles (Are men and women equal? Are roles going to be defined in terms of gender?). To these six, we would 
add two others: language (Will we teach our children two languages, and will one of us try to learn the language of the other partner?) and religion/ spirituality (Will we both have the same religion? How will the children be raised? How can we accept a different religious perspective in our spouse?). In addition, the couple's history of infidelity, attitudes about violence, sources of social support, and the couple's strengths not only may be assessed but also may be discussed and reflected on so that each member of the couple appreciates the unique perspective of his or her partner (Romano, 2008). This initial assessment process informs future treatment because it increases the couple's awareness and empathy. Another example of this kind of combined assessment-treatment intervention is the genogram.

\section{THE GENOGRAM AS A GENERIC TOOL}

One of the reasons that counselors and clients might neglect issues related to cultural intersection is the belief that one's own family is normal and happy (pseudomutuality; Wynne, Ryckoff, Day, \& Hirsch, 1958). This inherent familiocentrism and hidden ethnocentrism of each member of the couple make these issues invisible. For example, couples are not aware that when they insist on a certain wedding ceremony that they are enacting what has been passed down to them through their culture. The genogram is a simple tool that allows for this kind of exploration (Lim \& Nakamoto, 2008). A particular strength of the genogram is its ability to highlight acculturation and salience, the development of cultural identity, and cultural attraction, which may stem from family history.

The genogram is a picture of each person's background, and, in a couple, two genograms can be linked in a joint drawing (Long \& Young, 2007). For example, a couple can see the lines of substance abuse that exist in their family trees. For the multiple-heritage couple, the genogram can help the couple to understand the influences of the past that may be affecting present conflicts or present strengths (Hardy \& Laszloffy, 1995). Specific differences such as religion and spirituality can also be explored (Frame, 2001). Hardy and Laszloffy (1995) proposed a cultural genogram to promote cultural awareness and sensitivity in counselors. This tool can be adapted for working with multipleheritage couples to illustrate the influence that ethnicity, religion, language, and family values have on the relationship (Hardy \& Laszloffy, 1995).The genogram is a familiar graphic tool that the counselor can use as an entrée into the couple's combined world and that can establish understanding and empathy between the couple (McGoldrick, 2011).

\section{CARD SORTS}

Another technique suited to counseling is the Personal Wellness Card Sort (Lenz \& Roscoe, 2011). The card sort is a relationally based, creative intervention that aims at deepening self-awareness and connections with others (Lenz \& Roscoe, 2011). Individuals or couples divide cards into piles according to 
the degree to which they accurately describe each person or couple. Card sorts are interactive, and both the counselor and clients gain knowledge and awareness as they sort cards into piles that describe each individual and the couple. Card sorts have been used to help individuals to examine their ethnic self-identification (Casas, Ponterotto, \& Sweeney, 1987) and the development of multicultural competencies (Sue et al., 1998). The counselor can create the card sort so that it is individually tailored to the couple. Multiple-heritage couples can use the card sort to explore wellness beliefs and discuss themes related to relationship strengths.

\section{multicultural competencies and culturally appropriate couples counseling interventions}

The Association for Multicultural Counseling and Development Multicultural Counseling Competencies (MCCs; Arredondo et al., 1996; Sue, Arredondo, \& McDavis, 1992) include a number of guidelines for counselors who wish to become more culturally skilled. The MCCs address counselors' attitudes, knowledge, and skills related to their awareness of their own cultural values and biases, their awareness of the client's worldview, and culturally appropriate intervention strategies (Sue et al., 1992). For example, the MCCs state that, to be culturally skilled, counselors must be sensitive to their own cultural heritage, aware of their own cultural background and experiences, and knowledgeable about the particular client group (Sue et al., 1992). Additionally, culturally skilled counselors are those who possess knowledge of family structures and values in different cultures, exercise culturally appropriate interventions with their clientele, and attend to and work to eliminate individual biases they may have against certain cultures (Sue et al., 1992). Unfortunately, evidence suggests that trainees often fail to incorporate their knowledge of race and diversity issues into case conceptualization in couples therapy despite didactic learning (e.g., Schomburg \& Prieto, 2011).

As stated, it is a principle of multicultural counseling to understand and honor each member's background, yet, in couples counseling, there is a third client in the room-the couple itself. Couples of long standing generate their own combined family culture and pass that on to their offspring. Thus, it is crucial to assess this family culture as well as each member's background. One technique to address this issue is to assess the combined culture of the couple and ask the couple to normalize and formalize their creation. The couple will benefit through a process in which they develop their own story or narrative (Neal, Zimmerman, \& Dickerson, 1999). Sometimes the couple must rewrite its love story. The counselor can make this a formal written assignment in which the couple writes their story in a positive way, emphasizing the barriers they have overcome, the values they share, and what keeps their relationship 
strong. In the session, the counselor helps the couple to develop this mission statement into a positive declaration of their family's aims.

Besides supporting the couple's unique culture, the counselor must also be skilled in a variety of theories and techniques. Sue and Sue (1990) listed five characteristics of culturally effective counselors. The fifth characteristic is that counselors engage in an eclectic approach so that they have access to a wide range of counseling skills that can be adapted to the differing lifestyles of clients. The integrative model of couples counseling (Long \& Young, 2007; Young \& Long, 1997), which integrates narrative, solution-oriented, and strategic theoretical elements and allows for the inclusion of techniques from other schools of thought, has been used with multiple-heritage couples. The integrative model is brief and is designed to provide a pathway for those transitioning from individual to couples counseling in a systematic and step-by-step manner. In addition, the model's centerpiece is an interactive definition of the problem designed to bring together the divergent goals of two individuals into a common target. Thus, it is particularly appropriate for multiple-heritage couples because it is specifically aimed at helping the couple to find unity while respecting diversity. Two other brief integrative models with some research support are brief couples therapy (Chaim, Armstrong, Shenfeld, Kelly, \& Li, 2003) and brief strategic family therapy (Santisteban, Suarez-Morales, Robbins, \& Szapocznik, 2006). Brief integrative therapies are logical alternatives because they are flexible and have been shown to be effective. Another model with potential for the multiple-heritage couple is family of origin therapy à la Framo (Framo, Weber, \& Levine, 2003). Here, the counselor works with each member of the couple and their blood relatives to clear up family matters that might be affecting their relationship. This is a unique approach in which the family of origin gets together and uncovers anything that is left over from the past and that might be affecting the couple's current functioning as a family. Ultimately, the counselor might conduct a joint session with both spouses' families present and later with the couple alone.

In addition to couples and family therapy, marriage and relationship education, such as the Prevention and Relationship Enhancement Program (PREP), is appropriate for multiple-heritage couples (Blanchard, Hawkins, Baldwin, \& Fawcett, 2009). The PREP program is skills based and focuses on the attitude of the couple. In addition, the program allows for couples to brainstorm how to improve their relationship by considering small modifications and by building on successes (Blanchard et al., 2009). Some of the topics addressed in the PREP program include effective speaking and listening, problem solving, team building, and the role of fun in maintaining the couple relationship (Blanchard et al., 2009). A strength of the PREP program is that participants can view sessions as education rather than as therapy. Those who are wary of counseling may be more likely to attend. Although these couple relationship education programs may not specifically focus on culture and spirituality, 
they teach communication skills, which give couples the opportunity to talk about their differences in background and to consider common goals (Young \& Carlson, 2011). A key advantage of this kind of group counseling is that multiple-heritage couples have the opportunity to interact with and learn from similar couples, a process that might normalize any questions and concerns with their own relationship.

\section{conclusion}

Multiple-heritage couples are becoming more prevalent, and best practices suggest that counselors take into account the unique ethnic, racial, religious, and linguistic diversities in counseling. The term multiple heritage is offered as a replacement for the term biracial or bicultural when multiple differences apply. Certainly, multiple-heritage couples have special challenges and external pressures, and are the object of myths, misconceptions, and stereotypes that may influence the quality and stability of their relationship. Assessment and the use of the genogram and other tools are recommended for the purposes of thoroughly understanding each member and appreciating the couple as a whole. In addition, the counselor must be aware not only of the client's background but also the degree of acculturation and the amount of salience each member of the couple has for their cultural roots.

Multiple-heritage couples may experience skepticism about their union from society. Therefore, it is important that the counselor not participate in the pathologizing of the relationship and instead identify strengths. Brief, integrative work focusing on bringing the couple together rather than labeling seems especially appropriate for multiple-heritage couples (Long \& Young, 2007). In some cases, family-of-origin and combined family meetings may be useful. Couples classes (marriage and relationship education) are also positive psychoeducational approaches that build communication and understanding rather than focusing on what is wrong.

Although caring and being sensitive to culture is critical, so is learning how to work with couples. As in the case of group work and family therapy, an individually oriented counselor needs knowledge, skills, experience, and supervision to work with couples. We encourage the counselor to engage in thorough assessment, adopt an eclectic model of counseling, be open to psychoeducation, and have the courage to highlight the unique challenges and advantages experienced by multiple-heritage couples.

\section{references}

Arredondo, P., \& Perez, P. (2006). Historical perspectives on the multicultural guidelines and contemporary applications. Professional Psychology: Research and Practice, 37, 1-5.

Arredondo, P., Toporek, R. L., Brown, S. P., Jones, J., Locke, D. C., Sanchez, J., \& Stadler, H. (1996). Operationalization of the Multicultural Counseling Competencies. Journal of Multicultural Counseling and Development, 24, 42-78. 
Blanchard, V. L., Hawkins, A. J., Baldwin, S. A., \& Fawcett, E. B. (2009). Investigating the effects of couple and relationship education on couples' communication skills: A meta-analytic study. Journal of Family Psychology, 23, 203-214.

Bratter, J. L., \& King, R. B. (2008). "But will it last?" Marital instability among interracial and same-race couples. Family Relations, 57, 160-171. doi:10.1111/j.1741-3729.2008.00491.x

Byrd, M. M., \& Garwick, A. W. (2006). Family identity: Black-White interracial family health experience. Journal of Family Nursing, 12, 22-37. doi:10.1177/1074840705285213

Carbone-Lopez, K., Rennison, C. M., \& Macmillan, R. (2012). The transcendence of violence across relationships: New methods for understanding men's and women's experiences of intimate partner violence across the life course. Journal of Quantitative Criminology, 28, 319-346. doi:10.1007/s10940-011-9143-9

Casas, J. M., Ponterotto, J. G., \& Sweeney, M. (1987). Stereotyping the stereotypes: A Mexican American perspective. Journal of Cross-Cultural Psychology, 18, 45-57.

Chaim, G., Armstrong, S., Shenfeld, J., Kelly, C., \& Li, S. (2003). Brief couples therapy: Group and individual couple treatment for addiction and related mental health concerns. Toronto, Ontario, Canada: Centre for Addiction and Mental Health.

Chartier, K. G., \& Caetano, R. (2012). Intimate partner violence and alcohol problems in interethnic and intraethnic couples. Journal of Interpersonal Violence, 27, 1780-1801. doi:10.1177/0886260511430392

Chung, R. C., Bemak, F., Ortiz, D. P., \& Sandoval-Perez, P. A. (2008). Promoting the mental health of immigrants: A multicultural/social justice perspective. Journal of Counseling $\mathcal{E}$ Development, 86, 310-317. doi:10.1002/j.1556-6678.2008.tb00514.x

Clarkwest, A. (2007). Spousal dissimilarity, race, and marital dissolution. Journal of Marriage and Family, 69, 639-653. doi:10.1111/j.1741-3737.2007.00397.x

Crohn, J. (1995). Mixed matches. New York, NY: Ballantine.

Doherty, W. (2002, November/December). Bad couples therapy. Psychotherapy Networker, 9-13.

Forry, N. D., Leslie, L. A., \& Letiecq, B. L. (2007). Marital quality in interracial relationships: The role of sex role ideology and perceived fairness. Journal of Family Issues, 28, 1538-1552. doi: $10.1177 / 0192513 \times 07304466$

Frame, M. (2001). The spiritual genogram in training and supervision. The Family Journal, 9, $109-115$.

Frame, M. (2004). The challenges of intercultural marriage: Strategies for pastoral care. Pastoral Psychology, 52, 219-232. doi:10.1023/B:PASP.0000010024.32499.32

Framo, J. L., Weber, T., \& Levine, F. (2003). Coming home again: A family-of-origin consultation. New York, NY: Brunner/Routledge.

Fu, V. K. (2001). Racial intermarriage pairings. Demography, 38, 147-159. doi:10.1353/dem.2001.0011 Gottman, J. M. (1999). The marriage clinic: A scientifically based marital therapy. New York, NY: Norton.

Hardy, K. V., \& Laszloffy, T. A. (1995). The cultural genogram: Key to training culturally competent family therapists. Journal of Marital and Family Therapy, 21, 227-237.

Henricksen, R., \& Paladino, D. (2009). Counseling multiple heritage individuals, couples, and families. Alexandria, VA: American Counseling Association.

Hohmann-Marriott, B. E., \& Amato, P. (2008). Relationship quality in interethnic marriages and cohabitations. Social Forces, 87, 825-855.

Kenney, K. R., \& Kenney, M. E. (2012). Contemporary US multiple heritage couples, individuals, and families: Issues, concerns, and counseling implications. Counselling Psychology Quarterly, 25, 99-112. doi:10.1080/09515070.2012.674682

Killian, K. D. (2001a). Crossing borders: Race, gender, and their intersections in interracial couples. Journal of Feminist Family Therapy, 13, 1-31. doi:10.1300/J086v13n01_01

Killian, K. D. (2001b). Reconstituting racial histories and identities: The narratives of interracial couples. Journal of Marital and Family Therapy, 27, 27-42. doi:10.1111/j.1752-0606.2001.tb01137.x

Killian, K. D. (2002). Dominant and marginalized discourses in interracial couples' narratives: Implications for family therapists. Family Process, 41, 603-617. doi:10.1111/j.15455300.2002.00603.x 
Killian, K. D. (2003). Homogamy outlaws. Journal of Couple $\mathcal{E}$ Relationship Therapy: Innovations in Clinical and Educational Interventions, 2, 3-21. doi:10.1300/J398v02n02_02

Kluckhohn, F. R., \& Strodtbeck, F. L. (1961). Variations in value orientations. Oxford, England: Row, Peterson.

Kukutai, T. H. (2007). White mothers, brown children: Ethnic identification of Maori-European children in New Zealand. Journal of Marriage and Family, 69, 1150-1161. doi:10.1111/j.17413737.2007.00438.x

Kwan, K. (2005). Racial salience: Conceptual dimensions and implications for racial and ethnic identity development. In R. T. Carter (Ed.), Handbook of racial-cultural psychology and counseling: Vol. 1. Theory and research (pp. 115-131). Hoboken, NJ: Wiley.

Lebow, J. L., Chambers, A. L., Christensen, A., \& Johnson, S. M. (2012). Research on the treatment of couple distress. Journal of Marital and Family Therapy, 38, 145-168. doi:10.1111/j.17520606.2011.00249.x

Lee, J. L., \& Bean, F. D. (2004). America's changing color lines: Immigration, race/ethnicity, and multiracial identification. Annual Review of Sociology, 30, 221-242. doi:10.1146/annurev. soc.30.012703.110519

Lee, J. L., \& Bean, F. D. (2007). Reinventing the color line: Immigration and America's new racial/ethnic divide. Social Forces, 86, 561-586.

Lenz, A. S., \& Roscoe, L. J. (2011). Personal wellness card sort: A strategy for promoting relational healing. Journal of Creativity in Mental Health, 6, 69-83. doi:10.1080/15401383.2011.562755

Lewis, R. L., Yancey, G., \& Bletzer, S. S. (1997). Racial and nonracial factors that influence spouse choice in Black/White marriages. Journal of Black Studies, 28, 60-78.

Lim, S., \& Nakamoto, T. (2008). Genograms: Use in therapy with Asian families with diverse cultural heritages. Contemporary Family Therapy: An International Journal, 30, 199-219. doi:10.1007/s10591-008-9070-6

Long, L. L., \& Young, M. E. (2007). Counseling and therapy for couples (2nd ed.). Belmont, CA: Brooks/Cole.

Lorenzo-Blanco, E. I., Bares, C. B., \& Delva, J. (2013). Parenting, family processes, relationships, and parental support in multiracial and multiethnic families: An exploratory study of youth perceptions. Family Relations, 62, 125-139. doi:10.1111/j.1741-3729.2012.00751.x

Loving v. Virginia, 388 U.S. 1 (1967).

Mansikka, U., \& Fukuyama, M. A. (1985). Communication training for intercultural couples. Journal of College Student Personnel, 26, 254-255.

McGoldrick, M. (2011). The genogram journey: Reconnecting with your family. New York, NY: Norton.

Messer, S., \& Gurman, A. (2011). Essential psychotherapies. New York, NY: Guilford Press.

Neal, J., Zimmerman, J., \& Dickerson, V. (1999). Couples, culture, and discourse: A narrative approach. In J. M. Donovan (Ed.), Short-term couple therapy (pp. 360-400). New York, NY: Guilford Press.

Negy, C., \& Snyder, D. K. (2000). Relationship satisfaction of Mexican American and non-Hispanic White American interethnic couples: Issues of acculturation and clinical intervention. Journal of Marital and Family Therapy, 26, 293-304. doi:10.1111/j.1752-0606.2000.tb00299.x

Olver, K. (2012). Multicultural couples: Seeing the world through different lenses. In P. Robey, R. E. Wubbolding, \& J. Carlson (Eds.), Contemporary issues in couples counseling (pp. 33-46). New York, NY: Routledge.

Penn, C. D., Hernandez, S. L., \& Bermudez, J. M. (1997). Using a cross-cultural perspective to understand infidelity in couples therapy. The American Journal of Family Therapy, 25, 169-185. doi:10.1080/01926189708251064

Pew Research Center. (2009). Religiously mixed couples: Cupid's arrow often hits people of different faiths. Retrieved from http://www.pewforum.org/2009/02/10/religiously-mixed-couplescupids-arrow-often-hits-people-of-different-faiths /

Pew Research Center. (2012). The rise of intermarriage: Rates, characteristics vary by race and gender. Retrieved from http://www.pewsocialtrends.org/2012/02/16/the-rise-of-intermarriage/5/

Qian, Z., Blair, S. L., \& Ruf, S. D. (2001). Asian American interracial and interethnic marriages: Differences by education and nativity. International Migration Review, 35, 557-586. doi:10.1111/j.1747-7379.2001.tb00029.x 
Qian, Z., \& Licther, D. T. (2007). Social boundaries and marital assimilation: Interpreting trends in racial and ethnic intermarriage. American Sociological Review, 72, 68-94. doi:10.1177/000312240707200104

Romano, D. (2008). Intercultural marriage. Boston, MA: Nicholas Brealey Publishing.

Root, M. P. P. (2001). Love's revolution: Interracial marriage. Philadelphia, PA: Temple University Press.

Santisteban, D. A., Suarez-Morales, L., Robbins, M. S., \& Szapocznik, J. (2006). Brief strategic family therapy: Lessons learned in efficacy research and challenges to blending research and practice. Family Process, 45, 259-271.

Schomburg, A., \& Prieto, L. (2011). Trainee multicultural case conceptualization ability and couples therapy. Journal of Marital E Family Therapy, 37, 223-235. doi:10.1111/j.1752-0606.2009.00156.x

Skiba, R. J., Knesting, K., \& Bush, L. D. (2002). Culturally competent assessment: More than nonbiased tests. Journal of Child and Family Studies, 11, 61-78.

Sue, D. W., Arredondo, P., \& McDavis, R. J. (1992). Multicultural counseling competencies and standards: A call to the profession. Journal of Counseling E Development, 70, 477-486.

Sue, D. W., Carter, R. T., Casas, J. M., Fouad, N. A., Ivey, A. E., Jensen, M., . . .Vazquez-Nutall, E. (1998). Multicultural counseling competencies: Individual and organizational development. Thousand Oaks, CA: Sage.

Sue, D. W., \& Sue, D. (1990). Counseling the culturally different: Theory and practice (2nd ed.). New York, NY: Wiley.

Suzuki, L. A., \& Ponterotto, J. G. (2008). Multicultural assessment: Trends and future directions. In L. A. Suzuki \& J. G. Ponterotto (Eds.), Handbook of multicultural assessment: Clinical, psychological, and educational applications (pp. 666-671). San Francisco, CA: Jossey-Bass.

U.S. Census Bureau. (2003). 2001 statistical abstract of the United States. Retrieved from http:// www.census.gov/prod/www/statistical_abstract.html\#sa2001

Vandello, J. A., \& Cohen, D. (2003). Male honor and female fidelity: Implicit cultural scripts that perpetuate domestic violence. Journal of Personality and Social Psychology, 84, 997-1010. doi:10.1037/0022-3514.84.5.997

Weld, C., \& Eriksen, K. (2006). The challenge of religious conflicts in couples counseling. The Family Journal, 14, 383-391.

Wright, R., Houston, S., Ellis, M., Holloway, S., \& Hudson, M. (2003). Crossing racial lines: Geographies of mixed-race partnering and multiraciality in the United States. Process in Human Geography, 27, 457-474.

Wynne, L. C., Ryckoff, I. M., Day, J., \& Hirsch, S. I. (1958). Pseudomutuality in the family relations of schizophrenics. Psychiatry, 21, 205-220.

Yamawaki, N., Ochoa-Shipp, M., Pulsipher, C., Harlos, A., \& Swindler, S. (2012). Perceptions of domestic violence: The effects of domestic violence myths, victim's relationship with her abuser, and the decision to return to her abuser. Journal of Interpersonal Violence, 27, 3195-3212. doi: $10.1177 / 0886260512441253$

Yoon, E., Langrehr, K., \& Ong, L. (2011). Content analysis of acculturation research in counseling and counseling psychology: A 22-year review. Journal of Counseling Psychology, 58, 83-96. doi:10.1037/a0021128

Young, M. E., \& Carlson, R. G. (2011). Fragile families, fragile couples. Counseling and Human Development, 43, 1-12.

Young, M. E., \& Long, L. (1997). Counseling and therapy for couples. Belmont, CA: Brooks/Cole.

Zhang, Y., \& Van Hook, J. (2009). Marital dissolution among interracial couples. Journal of Marriage and Family, 71, 95-107. doi:10.1111/j.1741-3737.2008.00582.x 